(C) 2017, Elsevier. Licensed under the Creative Commons Attribution-NonCommercial-NoDerivatives 4.0 International http://creativecommons.org/licenses/by-nc-nd/4.0/

\title{
TYPE 2 DIABETES IN ADOLESCENTS AND YOUNG ADULTS
}

\section{AUTHORS}

Nadia Lascar MD; Aston University, School of Life and Health Sciences, Aston Triangle B4 7ET Birmingham, UK.

James Brown PhD; Aston University, Aston Research Centre for Healthy Ageing (ARCHA), Aston Triangle B4 7ET Birmingham, UK.

Helen Pattison; Aston University, School of Life and Health Sciences, Aston Triangle B4 7ET Birmingham, UK.

Anthony H. Barnett MD; Diabetes and Endocrine Centre, Heart of England NHS Foundation Trust and University of Birmingham, Birmingham B9 5SS, UK.

Clifford J. Bailey PhD; Aston University, School of Life and Health Sciences, Aston Triangle B4 7ET Birmingham, UK.

Srikanth Bellary MD; Aston University, Aston Research Centre for Healthy Ageing (ARCHA), Aston Triangle B4 7ET Birmingham, UK.

\section{ADDRESS FOR CORRESPONDENCE:}

Dr Srikanth Bellary

MB433L, Aston University

Aston Triangle, Birmingham B47ET

Email: s.bellary@aston.ac.uk

Tel: 01212044145 


\section{ABSTRACT}

The global prevalence of type 2 diabetes mellitus (T2DM) in adolescents and young adults is dramatically increasing. As with older onset type 2 diabetes, the major predisposing risk factors are obesity, family history and sedentary lifestyle. Onset of diabetes at a younger age is associated with longer disease exposure and increased risk for chronic complications affecting more individuals of working age and accentuating adverse societal impact of the disease. Evidence is also accumulating that young diabetic cohorts represent an aggressive phenotype leading to premature development of complications with an adverse impact on quality of life and unfavourably influencing long term outcomes, raising the possibility of a future public health catastrophe. In this review we describe the epidemiology and current knowledge regarding pathophysiology, risk factors, complications and management of type 2 diabetes in adolescents and young adults.

\section{KEY WORDS}

Type 2 diabetes, early-onset, young, youth, children, adolescents.

Word count: 5580 words (Not Including sub headings) 


\section{INTRODUCTION}

The global prevalence of adults with diabetes is around $8 \%$ ( $>90 \%$ of whom have T2DM)with projections to increase to over $10 \%$ by $2040^{1}$. While the impact of increasing prevalence of diabetes among older adults is becoming ever more apparent, the rising number of young people with T2DM(T2DMY) is a more recent and particular concern. Earlier onset leads to longer lifetime exposure to hyperglycaemia and consequently greater propensity for long term complications. In addition, T2DMY may have a more rapid and disruptive natural history than T2DM presenting later in life, leading to early morbidity and poor quality of life ${ }^{2}$. Moreover,T2DMY affects more individuals of working age which further accentuates its adverse societal impact.

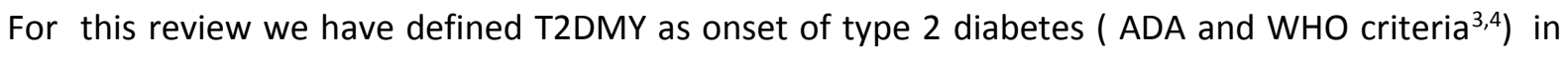
adolescents and young adults up to age 40 years excluding secondary diabetes (drug- or chemicalinduced, exocrine pancreas disease, genetic defects), MODY, gestational diabetes and rare forms of diabetes. We examine evidence in support of the hypothesis that T2DMY is a distinct pathological entity characterised by a more aggressive phenotype than T2DM presenting in later life.

\section{SEARCH STRATEGY AND SELECTION CRITERIA}

References were identified through searches of Medline, PubMed and Web of Science for articles published January 2000 to April 2017. Search terms included "early-onset", "young adults", "youth", "children", and "adolescents" in combination with the term "diabetes" and "type 2 diabetes". Studies had to be in human populations, published in English and with a defined age-range for diagnosis of T2DMY. Articles were excluded if they were case reports, editorials, small studies or studies that the authors felt had methodological limitations, studies on type 1 diabetes, gestational diabetes or MODY. Although T2DM across adolescents and younger adults can be seen as a continuum, inevitably there are some distinct features within age groups that are influenced by life events at different ages. To provide further clarity of such distinctions, we have identified studies that have included only a specific age range.

\section{EPIDEMIOLOGY}

T2DM is increasingly diagnosed in children, adolescents and younger adults. Prevalence estimates suggest a 30.5\% increase in T2DM amongst US youth aged 10 to 19 years between 2001 and 2009, accounting for prevalence of 0.48 per 1000 in this age group ${ }^{5}$. Recent data from the SEARCH study showed an annual increase of 7.1\% in the incidence of T2DM (9 cases per 100,000 in $2002-2003$ to 12.5 cases per 100,000 in 2011-2012) amongst 10-19 year olds in the USA with significant relative increases in all ethnic groups compared to non Hispanic Whites ${ }^{6}$. A nationwide screening programme of diabetes among children aged 6 to 18 years, in Taiwan between 1992 and 1999, found an incidence of newly diagnosed T2DM of 6.5 per 100,000 compared with 1.5 per 100,000 for $\mathrm{T}_{1 \mathrm{DM}}{ }^{7}$.The International Diabetes Federation estimated that in the year 2000 young adults aged $20-$ 39 years with T2DM numbered approximately 23 million worldwide (13\% of 177 million adults with diabetes $^{8}$ ). By 2013 this had increased to an estimated 63 million (16\% of 382 million adults with 
$\mathrm{T}^{2} \mathrm{DM}^{9-11}$ ), the biggest increases being in Africa, South East Asia and the Western Pacific regions (Figure 1).

Figure 1. Young adults (20-39 years) with T2DM worldwide (millions) ${ }^{9}$



* refers to $\%$ of Total number of people diagnosed with type 2 diabetes

A study of the age specific incidence of T2DM in the UK reported a significant increase in the proportion of people aged $\leq 40$ years at diagnosis (Figure 2 ) $^{12}$ over a 20 year period. The standardized incidence ratio (per 100,000 population) of newly diagnosed T2DM aged $<40$ years increased from 217 in 1996-2000 to 598 in 2006-2010. 
Figure 2. Age specific incidence of newly diagnosed T2DM per 100,000 amongst males and females aged less than 40 years at diagnosis (modified with permission) ${ }^{12}$

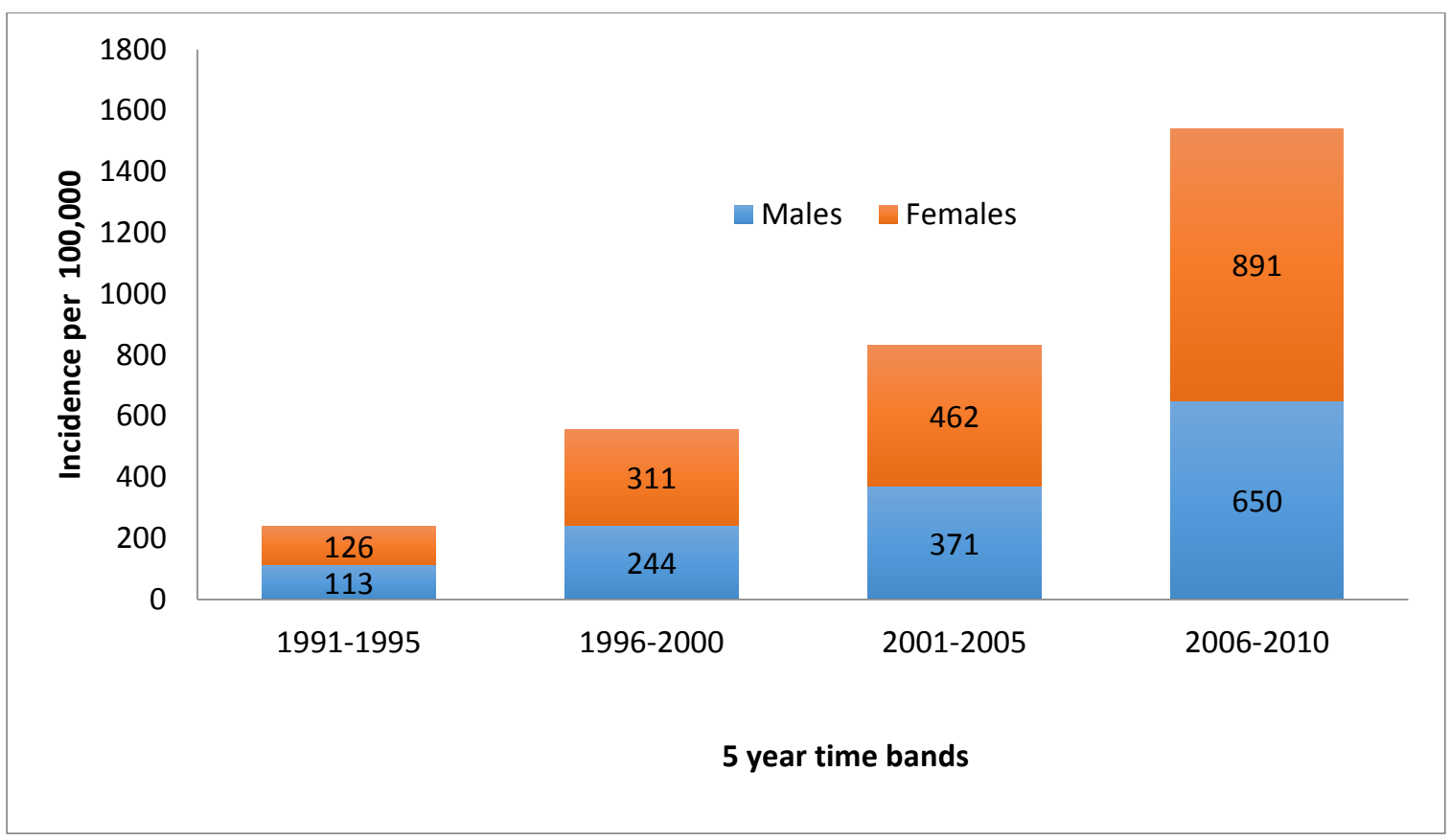

Increasing numbers of children, adolescents and young adults with T2DM have been reported across most regions of the world. In the UK, a higher prevalence is reported in people of South Asian, African and African-Caribbean origin compared with white European populations ${ }^{13}$. Individuals born in the USA in the year 2000 have a risk for diabetes by age 40 years of approximately $2.5 \%$ for men and $5 \%$ for women., These estimates are doubled for Hispanic and black persons suggesting that certain ethnic groups are disproportionately affected ${ }^{14}$. However, apparent ethnic differences based on regional variations in prevalence (table 1), have the limitation that the diagnostic criteria and methods of data collection are not always consistent ${ }^{15-17}$.

\section{PATHOPHYSIOLOGY}

\section{Decline in beta cell function}

The mechanisms leading to development of T2DMY are similar to those in T2DM amongst older adults. However, the speed of onset, severity and interplay of decreased insulin sensitivity and defective insulin secretion during the development of T2DMY may differ from older presentations of $\mathrm{T}_{2} \mathrm{DM}^{18}$. In adolescents with T2DM, as in later onset T2DM, the initial deterioration in beta-cell 
function is characterised by loss of first phase nutrient-stimulated insulin secretion ${ }^{6}$. However, the second phase of nutrient-induced insulin secretion may be compromised earlier in the pathogenic process in younger individuals with $\mathrm{T}_{2} \mathrm{DM}^{18,19-}$. A case-control study of African-American and white Europids found that obese adolescents with T2DM for about 1.5 years have about a $75 \%$ decrease of first phase and a $50 \%$ decrease of second phase insulin secretion compared with obese non diabetic peers ${ }^{20}$. Such a decrease in second phase insulin secretion would take more than a decade to emerge in most T2DM patients presenting in middle or later life ${ }^{21-22}$. Emerging evidence suggests that loss of beta cell function is accelerated in T2DMY. A 20-35\% decline in beta cell function annually in 10-19 year olds has been reported compared to the $7 \%$ loss in older individuals with $\mathrm{T}_{2 \mathrm{DM}}{ }^{23}$. These findings are consistent with data from a small but detailed clamp study in this age group $^{24}$. Separate observational studies in adolescents of different ethnic groups have similarly confirmed the early deterioration of beta-cell function with T2DMY: this was closely associated with the severity of insulin resistance (IR) in African-American adolescents but less so in white Europids and South Asians ${ }^{25,26}$. Thus, accelerated decline of beta cell function appears to make an important contribution to the development of T2DM in early life. The reasons for this rapid failure of both phases of nutrient-stimulated insulin secretion are unclear but suggest that T2DMY may have more aggressive course with faster loss of beta cell function than T2DM presenting later in life.

\section{Obesity induced mechanisms}

The prevalence of obesity among children, adolescents and young adults with T2DM is much greater than in older adults (eg. $>80 \%$ versus $56 \%$ in a recent study ${ }^{26}$ ) and analyses of large databases have confirmed a strong inverse association between $\mathrm{BMI}$ and age at diagnosis of T2DM ${ }^{27}$. When T2DM presents in later life the severity of IR is often greater amongst those with a history of protracted and severe obesity, particularly with excess visceral adiposity ${ }^{28}$. In contrast, a relationship between the degree of obesity and the extent of IR has not been a consistent finding in studies of adolescents with T2DM, and there are insufficient data to determine the involvement of visceral adiposity in this age group ${ }^{19}$. However, IR is directly related to an increased percentage of fat in muscle and liver in all age groups ${ }^{6}$, and younger people with T2DM can have much higher (up to 3 times) amounts of liver fat compared with BMI-matched non-diabetic controls and compared with presentations of T2DM in middle and later life ${ }^{24,}$

Compared with non-obese adolescents, obese adolescents are reported to have chronically increased circulating free fatty acids (FFA) which decrease insulin sensitivity and may contribute to increased reactive oxygen species and impair insulin secretion ${ }^{29}$. Chronic low-grade inflammation contributes to development of insulin resistance in T2DM, typically involving excess production of adipokines (tumour necrosis factor- $\alpha$ (TNF $\alpha$ ), interleukin -1beta and high sensitivity C-reactive protein ${ }^{29,30}$. Increased circulating concentrations of these pro-inflammatory markers are reported in adolescents with $\mathrm{T}^{2} \mathrm{DM}^{30}$. While obesity is clearly a prominent risk factor for T2DMY, studies focussed on IR, lipid metabolism and inflammation corroborate evidence in the previous section suggesting that the development of 'diabetic' hyperglycaemia in this age group appears to be more strongly dependent on beta-cell failure than T2DM in later life. 


\section{KEY DRIVERS FOR T2DMY}

\section{Early life determinants}

Changes in the intrauterine environment influence development of obesity and type 2 diabetes in adolescents and young adults more strongly than in later life. Maternal undernutrition and overnutrition are associated with a greater increased risk of obesity and type 2 diabetes in adolescence and early adulthood than in later life, ${ }^{31,32}$. This may depend in part on the extent and timing of 'catch-up' growth in underweight offspring and the extent of excess adiposity in those with overnutrition sustained beyond the first year of life ${ }^{33}$. Thus, in a large prospective study, rapid weight gain during the first 4 months of life was associated with an increased risk of overweight at age 7 years ${ }^{34}$, while post-partum under nutrition increased the risk of obesity and type 2 diabetes in young adults ${ }^{35}$. Also, T2DM before age 20 years emerges 1-2 years earlier in offspring exposed to hyperglycaemia in utero ${ }^{31}$. These observations have been attributed in part to epigenetic influences of the intra-uterine and early post-natal environment on metabolic programming, but the molecular mechanisms remain speculative ${ }^{36}$.

\section{Diet and obesity}

The global pandemic of overweight and obesity now affects $36.9 \%$ of men, $38 \%$ of women, $23.8 \%$ of boys and $22.6 \%$ of girls ${ }^{37}$. Although the causes of obesity in children and adolescents are complex, obesity is clearly a driver for the upsurge in T2DMY and changes in lifestyle account for much of the increased prevalence of obesity and T2DM in pre- and early- adult life ${ }^{38}$. Increasing consumption of calorie dense foods, and sugar-rich drinks and decreased physical activity are the main contributors amongst youth ${ }^{39}$. Regular consumption of sweetened beverages increases energy consumption by about $10 \%$, while increased portion sizes, access to fast foods and targeted advertising of snacks increase adiposity in children, adolescents and young adults ${ }^{40,41}$. The widespread use of corn derived fructose syrup as a sweetening agent in 'fizzy' drinks has a substantial impact on development of adiposity, IR, hyperglycaemia and other cardio-metabolic risk factors in the young ${ }^{42,43}$. Indeed, the SEARCH study showed few differences in macronutrient or fibre intake between youths with T1DM versus T2DM, but those with T2DM consumed twice the amount of sweetened beverages ${ }^{44}$.

\section{Physical activity}

Physical inactivity is associated with increased risk of obesity. However, owing to methodological deficiencies and lack of reliable baseline data, it is difficult to quantify the secular changes in leisure time activity in adolescents and younger adults ${ }^{45}$.Nevertheless, better transportation, television viewing and video games all contribute to sedentary behaviours ${ }^{45}$. Physical activity declines further in adolescents compared with younger children and only a small proportion meet recommended levels, eg recent surveys in Europe and North America indicate that about $80 \%$ of $13-15$ year-olds 
undertake moderate or vigorous exercise for less than 60 minutes per day, with girls being less active than boys ${ }^{46-49}$. Physical inactivity amongst youth is associated with increased risk of metabolic syndrome, insulin resistance and type 2 diabetes. ${ }^{50-51}$.

In the Bogulusa Heart Study of young adults aged 20-38 years, an inverse relationship was observed between leisure time physical activity and risk factors for insulin resistance ${ }^{50}$. Similarly, in the CARDIA study of 18 to 30 year olds, there was a strong association between physical inactivity and risk of type 2 diabetes, hypertension and metabolic syndrome ${ }^{51}$. Although aerobic exercise can delay or prevent the development of type 2 diabetes in older adults, the expected metabolic benefits derived from aerobic activity are comparatively less in those with T2DMY ${ }^{52}$. Thus, while lack of physical activity makes an important contribution to the pathogenesis of T2DMY the potential for increased physical activity as a treatment strategy needs further elucidation.

\section{Socio-economic factors}

Socio-economic deprivation within affluent societies is a risk factor for obesity and type 2 diabetes especially amongst inner city populations. For young individuals at least, this is attributable more to lifestyle choices for energy dense 'convenience' foods and sedentary habits than an absolute lack of availability or affordability of healthier options, often reflecting educational factors and local practices ${ }^{54,56}$. The impact of deprivation is magnified by the predisposition to T2DM across certain ethnic migrant communities ${ }^{57}$. However, it is difficult to dissect the contributions of genetic determinants, environmental influences and cultural constraints, especially for pre-adult and early adult development of T2DM ${ }^{54-56}$

Socio-economic interventions can relieve absolute deprivation but do not necessarily alter individual lifestyle choices. Thus, re-housing or changing facilities within neighbourhoods can bring about modest reductions in the incidence of obesity and T2DM, but the complex interactions of multiple diabetogenic factors continue to mask appreciation of the contribution of individual determinants of risk ${ }^{58-59}$. Indeed, obesity is also common amongst members of affluent societies who are not deprived, and this cannot be accounted for by ethnicity or culture, thereby implicating individual lifestyle and behavioural choices as risk factors having a greater influence on the pathogenesis of T2DMY ${ }^{60-61}$.

\section{Other risk factors}

\section{Family history}

There is an inverse association between the strength of a family history of T2DM and age of onset of $\mathrm{T}_{2} \mathrm{DM}^{62}$. In a study of 5193 subjects from different ethnic backgrounds, including Anglo-Celtic, Indian, Australian Aboriginal and Pacific Islander, age of onset of diabetes reduced by 1.7 years for every $10 \%$ increase in family members affected by diabetes ${ }^{62}$. Similar associations occur in Korean ${ }^{9}$, Chinese $^{63}$ and Indian populations ${ }^{64}$. In white Europeans, T2DM patients diagnosed at $<55$ years had a stronger and different genetic predisposition than subjects diagnosed later ${ }^{65}$. In a large Scottish population-based cohort study, genetic risk of T2DM conferred by 61 gene variants was associated with a younger age at diagnosis and younger age at insulin treatment ${ }^{66}$. Although parental diabetes 
strongly influences early-onset T2DM, it is difficult to disentangle genetic and socially-acquired factors. For example, increased risk of T2DMY amongst Afro-Caribbean and South Asian communities is strongly influenced by cultural factors, especially amongst women, but attempts to analyse this through studies of migrant individuals have noted the tendency of migrants to adopt a mix of cultures that still precludes dissection of specific risk factors ${ }^{67-69}$.

Studies in Mexican and Asian populations have identified several mutations associated with $\mathrm{T}^{2} \mathrm{DMY}^{70-73}$. The high prevalence of parental T2DM in subjects diagnosed with T2DMY could reflect a stronger genetic predisposition, even when monogenic diabetes is excluded. This suggests that efforts to define T2DM genes by linkage may be more powerful if focused on young adults with diabetes, raising the question whether T2DM in older populations has a relatively smaller genetic and a stronger environmental influence ${ }^{65}$.

\section{Gender and Polycystic ovarian syndrome (PCOS)}

T2DMY is more common amongst females across all ethnicities. Incidence rate amongst females was nearly twice that of males in the SEARCH study 6 . Female gender is associated with early-onset diabetes ( $<30$ years) in Bangladesh ${ }^{74}$ and Jamaica ${ }^{75}$, attributed to the increase in overweight and obesity. Gestational diabetes is a risk factor for T2DM and can trigger onset of T2DM in youth ${ }^{76}$. The risk of T2DM is significantly elevated in young women diagnosed with PCOS, and is possibly related to insulin resistance ${ }^{77,78}$. The Australian Longitudinal Study on Women's Health found that in women aged 28-33 years and of similar BMI, the prevalence of T2DM was 5.1\% in women with and $0.3 \%$ in women without PCOS ${ }^{76}$. Studies in the USA and Asia of women aged 20-35 years, report a three-fold increased rate of T2DM in those with PCOS compared with the general population ${ }^{77}$.

\section{Non-alcoholic fatty liver disease (NAFLD)}

Non-Alcoholic Fatty Liver Disease (NAFLD) appears to be a stronger risk factor for T2DMY than presentations of T2DM in middle and later life .NAFLD is often doubled in adolescents and young adults with T2DM, alongside insulin resistance and hyperinsulinaemia ${ }^{79-80}$. An Indian study noted a 54.7\% prevalence of NAFLD in patients with T2DM aged 25-40 years, with liver enzymes being higher than patients aged $>40$ years ${ }^{81}$. In a cross-sectional study across 12 centres in the USA, biopsyconfirmed NAFLD was $43 \%$ higher in children ( $<18$ years of age) with T2DM and $34 \%$ higher in children with pre-diabetes than non-hyperglycaemic peers ${ }^{82}$. The extent to which excess ectopic fat and particularly NAFLD are driving insulin resistance in T2DMY remains unclear, but alcohol does not appear to be a significant cause of fatty liver in this age group.

\section{CLINICAL CHARACTERISTICS}

The clinical characteristics of T2DMY show substantial overlap with type 1 diabetes mellitus (T1DM) and T2DM from which it needs to be differentiated. The early loss of insulin secretory capacity in pre-adult and early adult presentations of T2DM is similar to the demise of beta-cell function in T1DM, while the high degree of obesity seen in T2DMY is an exaggeration of that seen with later 
adult-onset T2DM. Adolescents who develop T2DM also typically show similar clinical features of insulin resistance, dyslipidaemia, hypertension and PCOS to later presentations of T2DM, but the long-term consequences of early-onset complications are only now becoming apparent ${ }^{83-84}$.

Despite the shared clinical characteristics, T2DMY can be differentiated from T1DM and T2DM based on certain phenotypic characteristics (Table 1). Compared to T1DM,individuals with T2DMY do not have evidence of autoimmunity and typical symptoms of diabetes may be absent in a third of all patients ${ }^{85}$. They have a higher prevalence of hypertension and a greater adverse cardiovascular risk profile than with T1DM and are more likely to be on statins and anti-hypertensives ${ }^{86,87,89}$. There is also a higher prevalence of microvascular complications at a shorter disease duration compared to T1DM $^{88}$.

Compared to late onset T2DM, a significant proportion (around 65\%) of individuals with T2DMY are diagnosed based on self reported symptoms than through regular health checks ${ }^{85}$ and have a higher prevalence of a diabetes family history, diastolic hypertension and worse glycaemic control 26,27 . Furthermore, T2DMY is associated with a shorter time to start insulin than T2DM in older adults ${ }^{89,90}$.

Table 1: Differences between T1DM, T2DMY and T2DM

\begin{tabular}{|c|c|c|c|}
\hline & T1DM & T2DMY & T2DM \\
\hline Gender & No difference & Female preponderance & Slight male preponderance \\
\hline Ethnicity & $\begin{array}{l}\text { Common in white Caucasians } \\
\text { although all ethnic groups } \\
\text { affected }\end{array}$ & $\begin{array}{l}\text { All ethnic groups but Hispanics, } \\
\text { African -Americans, native } \\
\text { Americans and South Asians } \\
\text { disproportionately more affected }\end{array}$ & $\begin{array}{l}\text { All ethnic groups but Hispanics, } \\
\text { African -Americans, native } \\
\text { Americans and South Asians } \\
\text { more affected }\end{array}$ \\
\hline Clinical features & $\begin{array}{l}\text { Often underweight, sometimes } \\
\text { mildly obese } \\
\text { Features of insulin resistance less } \\
\text { likely }\end{array}$ & $\begin{array}{l}\text { Usually overweight, obese or } \\
\text { severely obese } \\
\text { Metabolic Syndrome } \\
\text { Insulin resistance, dyslipidaemia, } \\
\text { hypertension, PCOS }\end{array}$ & $\begin{array}{l}\text { Usually overweight, obese or } \\
\text { severely obese } \\
\text { Metabolic Syndrome } \\
\text { Insulin resistance, dyslipidaemia, } \\
\text { hypertension, PCOS }\end{array}$ \\
\hline Autoimmunity & Present & Absent & Absent or rare \\
\hline Presentation & Often acute onset/ketoacidosis & $\begin{array}{l}\text { Slow/asymptomatic/rarely } \\
\text { ketoacidosis }\end{array}$ & Slow/asymptomatic \\
\hline Family history & Commonly no family association & Very strong & Strong \\
\hline Diabetes Management & Insulin & $\begin{array}{l}\text { Rapid progression to insulin } \\
>50 \% \text { between } 2-5 \text { years since } \\
\text { diagnosis }\end{array}$ & $\begin{array}{l}\text { Gradual progression to Insulin } \\
\text { Usually }>5 \text { years since diagnosis }\end{array}$ \\
\hline
\end{tabular}

Individuals with T2DMY develop adverse metabolic and cardiovascular risk profiles more rapidly and much sooner after diagnosis than T2DM in middle and later life ${ }^{91}$. Whilst the features associated with these adverse risk profiles are not dissimilar a greater intensity and greater potential impact on complications is likely ${ }^{87}$. For example, a higher prevalence of obesity and metabolic syndrome (up to $70 \%$ ) has been reported in individuals with T2DMY and sub-diabetic hyperglycaemia (IFG and 
IGT),91,92. Early-onset of T2DM in adults has also been associated with a higher HbA1c in US ${ }^{9}$, Asian ${ }^{10}$ and $U K^{93}$ populations. In a large proportion of young adult Sri Lankan patients with T2DM, aged 14-45 years (median age 38yrs), there were increased apolipoprotein B (54\%>1.2 g/L) and triglycerides $(33 \%>1.5 \mathrm{mmol} / \mathrm{L})$, consistent with increased $\mathrm{CV}$ risk $^{94}$. Similar results were reported in a UK population ${ }^{95}$. Moreover, apolipoprotein B levels remained significantly higher among earlyonset T2DM subjects compared to older adults with T2DM despite statin treatment supporting the elevated atherogenic risk in the former ${ }^{94,96}$.

\section{COMPLICATIONS}

Earlier onset of type 2 diabetes is associated with a greater lifetime risk of diabetes-related complications ${ }^{97}$. Several cross-sectional studies have suggested that the burden of diabetes complications is greater for T2DMY than T1DM and later onset T2DM. Overall life expectancy amongst those diagnosed with T2DM at 20-40 years is reduced by 14 years in men and 16 years in women, ${ }^{98}$ compared to the non-diabetic population.

\section{Microvascular complications}

Studies have reported a significantly higher prevalence of microvascular complications in T2DMY compared to T1DM and later onset T2DM ${ }^{102,103,106}$. The burden of microvascular complications and co-morbidites (diabetic kidney disease, retinopathy and peripheral neuropathy) was significantly greater amongst adolescents and youth with T2DM compared to those with T1DM in the SEARCH study ${ }^{106}$. In studies comparing patients with T1DM and T2DMY, rates of microalbuminuria were significantly greater in the latter and associated with a faster progression to macroalbuminuria ${ }^{107}$. T2DMY also had a four times greater risk of renal failure and relatively poor survival outcomes when compared with T1DM of a similar age and diabetes duration ${ }^{9,27,92,102}$. In a longitudinal observational multi-ethnic cohort study of young people in the USA with T2DM diagnosed at $<20$ years of age, the prevalence of diabetic peripheral neuropathy was comparable to that reported in older adults with T2DM and three times higher when compared to young people with T1DM ${ }^{107}$. In a UK study, the prevalence of retinopathy at all stages amongst T2DMY patients (age of onset <40years) was comparable with T1DM patients despite a shorter duration of diabetes and similarly poor glycaemic control, but there was a higher prevalence when corrected for diabetes duration ${ }^{104}$. An increased frequency of retinopathy, advanced eye disease and photocoagulation was noted in a large retrospective study of early onset versus late onset T2DM subjects in Asia ${ }^{105}$. Another study found that 10 years after diagnosis prevalence of retinopathy amongst T2DMY patients was significantly higher than those with later onset T2DM, and identified hypertension and suboptimal glycaemic control as predominant contributing risk factors ${ }^{103}$.

\section{Macrovascular Complications}

Compared to non-diabetic individuals of similar age, T2DMY subjects have a substantially greater risk of macrovascular disease ${ }^{89}$. In a large prospective study comparing earlier versus later onset of 
T2DM in adults (mean age at diagnosis 37.6 years $v 60$ years), the risk of developing any macrovascular complication was twice as high in those with earlier onset ${ }^{108}$. Further, T2DMY patients had a 14-fold higher risk of developing an MI than non-diabetic control subjects, whereas the risk of an MI would be much less (typically 2-4 fold higher) in T2DM presenting in middle and later life ${ }^{108}$. In Hong Kong, where $20 \%$ of recently diagnosed T2DM occurs in those aged $<40$ years, a 7 year prospective study reported that when adjusted for age patients with T2DMY had 30-50\% excess risk of $\mathrm{CV}$ and renal disease compared with late-onset disease ${ }^{109}$. At diagnosis the T2DMY patients had a similar or worse metabolic risk profiles compared with late-onset disease, and the risks for $\mathrm{CV}$ and renal complications at any given age were greater in T2DMY, predominantly driven by longer disease duration ${ }^{109}$. During the sixth decade, T2DMY was associated with approximately double the risk of CVD, CKD and all-cause mortality ${ }^{109}$.

Significant differences in surrogate markers of CV disease between T1DM, later onset T2DM and T2DMY are reported ${ }^{110-112}$. Compared with T1DM and young control subjects, T2DMY patients (aged 14-30 years) show a greater frequency of increased carotid intimal-medial thickness (IMT) ${ }^{110-}$ ${ }^{112}$.In an audit of 354 young adult patients with T2DM aged 15 to 30 years marked increase of macrovascular disease in T2DMY compared to T1DM, including ischaemic heart disease and stroke was reported in an Australian hospital diabetes database ${ }^{112}$. While it is difficult to draw definitive conclusions from these observational studies, they suggest that T2DMY is associated with a much more frequent occurrence of adverse macrovascular and microvascular outcomes and a more rapidly progressing severity of complications than TIDM or later-onset T2DM.

\section{Other complications}

Complications such as impaired hearing and reduced fertility are frequent in T2DMY and these can substantially reduce quality of life ${ }^{113-115}$. Risk of premature decline in cognitive function has been detected in T2DM presenting in middle and later life, and preliminary evidence suggests this could be even earlier in T2DMY and have an important impact on healthcare and social welfare ${ }^{116,117}$

\section{TREATMENT}

There is little evidence to inform optimal strategies for the management of T2DMY and its rapidly developed complications: decisions are currently extrapolated from the evidence-based protocols that guide treatment of T2DM presenting in older adults. The American Academy of Paediatrics ${ }^{2}$ and the ADA guidelines ${ }^{127}$ agree that the ideal goal of treatment in youth with T2DM is normalisation of glycaemic control to reduce the risk of acute and chronic complications. Lifestyle modifications are prioritised, while approved pharmaceutical agents can be considered in addition when lifestyle alone is inadequate. The AACE guidelines ${ }^{128}$ support a general approach that balances age, life expectancy and comorbidities, but there is no specific guidance according to age groups. 
Although lifestyle modification is the most commonly used intervention in adolescents with T2DM, $<20 \%$ achieve or maintain adequate glycaemic control with lifestyle therapy alone ${ }^{129,133}$. Interventions involving diet alone to treat T2DMY have been limited. A retrospective study of 20 obese children and adolescents (mean age 14.5years) with T2DM reported improvements in weight (BMI fell from 43.5 to $39.3 \mathrm{~kg} / \mathrm{m}^{2}$ ), insulin sensitivity and $\mathrm{HbA1c}$ after introduction of a very low $(<800 \mathrm{Kcal} /$ day) calorie diet over a 2 month period. These improvements were, however, not maintained following cessation of the diet ${ }^{131}$.

Aerobic activity, alone or in combination with diet, can reduce systolic blood pressure, lower total cholesterol, raise HDL-cholesterol and improve endothelial function in overweight T2DMY ${ }^{53}$. However, any potential benefits to the $\mathrm{CV}$ risk profile are lost within 3-6 months following cessation of exercise training, and do not confer protection against later CV events ${ }^{53,133}$. Moreover, reviews of the limited number of studies to date have not identified significant or lasting benefits on glucose homeostasis of obese T2DMY patients undertaking additional aerobic exercise unless accompanied by dietary intervention ${ }^{53,132,133}$.

\section{Pharmacological approaches}

There remains great uncertainty in those younger than 18 years where concerns or lack of information about safety preclude or deter the use of many novel therapies. This is compounded by difficulties recruiting younger people into clinical trials. Both metformin and glibenclamide can be used effectively, at least in the short-term, in children and adolescents with T2DM. Reduction in fasting plasma glucose ( $1.2 \mathrm{mmol} / \mathrm{l})$ and $\mathrm{HbA} 1 \mathrm{c}>1 \%$ has been reported with metformin monotherapy in children with T2DM aged 10 to 16 years ${ }^{135}$. Significant lowering of HbA1c was also shown in a study comparing metformin and glibenclamide as monotherapy and in combination: interestingly, the combination was no more effective than either of these agents used alone ${ }^{136}$

Sustainability of glycaemic control with metformin +/- rosiglitazone was examined in the TODAY study - a randomised controlled trial of up to 6 years in a multiethnic cohort of 699 adolescents with T2DM diagnosed age 10-17 years ${ }^{137-138}$. Despite good treatment compliance, metformin as monotherapy or in combination with either rosiglitazone or lifestyle failed to sustain effective glycaemic control. At 1 year, treatment failure with metformin monotherapy was seen in $51.7 \%$, compared to $46.6 \%$ in metformin plus lifestyle and $38.6 \%$ in the metformin plus rosiglitazone groups. $\mathrm{High} \mathrm{HbA1c}$ and low insulin secretory capacity at baseline were independent predictors of risk for treatment failure (defined as $\mathrm{HbA} 1 \mathrm{c}>8 \%$ for 6 months) ${ }^{137}$. The study also highlighted ethnic differences in response to treatment with high failure rates amongst non-Hispanic blacks ${ }^{137}$ (Table 2).

Rapid decline in beta-cell function may largely explain the faster loss of glycaemic control and the earlier requirement for insulin therapy in T2DMY than in T2DM (ref). Although some adolescents with T2DM can maintain glycaemic control for the first 2-3 years after diagnosis using lifestyle and metformin interventions ${ }^{90}$, insulin is often preferred as the initial therapy and about one third of those receiving basal insulin are able to subsequently stop insulin as glycaemic control improves ${ }^{90,94}$. About half of these patients require re-initiation of insulin within a few months because of poor 
control and some will require substantial insulin intensification ${ }^{94}$. Based on the limited evidence to date, the types of insulins selected and the monitoring methods seem to make little difference to the glycaemic control achieved or the complication status ${ }^{139}$. Current evidence has not established a reduction in adverse $\mathrm{CV}$ events with rigorous control of CV risk factors in adolescents with T2DM. Several studies have reported that typically less than a third of these patients achieve their glycaemic or lipid targets and are less likely to be prescribed lipid lowering treatments, reninangiotensin-system inhibitors or anti-platelet agents than T2DM patients presenting in later life ${ }^{140-}$ 143 .

Although many clinical trials in T2DM include individuals from age 18 onwards there are usually few young adults recruited and little data specific to the effectiveness of treatments in the age range 1840. Treatment approaches in this age group are therefore based on evidence from older T2DM ${ }^{134}$. Several oral and injectable glucose lowering therapies are approved for T2DM and offer a wide choice in selecting appropriate therapeutic combinations. Many of these agents such as the DPP4 inhibitors, GLP-1 agonists and SGLT2 inhibitors have beneficial effects on weight, insulin resistance and beta cell preservation. Whether they have a more favourable effect on the disease course in youth needs further investigation.

\section{Bariatric Surgery}

This has emerged as a viable treatment option in individuals with T2DM ${ }^{144}$ and there is now evidence that it is safe and effective in obese adolescents ${ }^{145-146}$. Data in youth with type 2 diabetes are limited but nevertheless encouraging with significant improvements in weight and glycaemic indicators as seen in older adults (ref). 


\begin{tabular}{|c|c|c|c|c|c|c|c|c|}
\hline STUDY & $\begin{array}{l}\text { STUDY } \\
\text { TYPE }\end{array}$ & $\begin{array}{r}\text { NUMBER } \\
\text { of Subjects }\end{array}$ & ETHNICITY & $\begin{array}{l}\text { AGE } \\
\text { RANGE } \\
\text { (YEARS) }\end{array}$ & $\begin{array}{l}\text { DIABETES } \\
\text { DURATION } \\
\text { (YEARS) }\end{array}$ & $\begin{array}{l}\text { INTERVENTION } \\
\text { AND FOLLOW UP }\end{array}$ & $\begin{array}{l}\text { FOLLOW UP } \\
\text { (MONTHS) }\end{array}$ & GLYCAEMIC OUTCOMES \\
\hline $\begin{array}{l}\text { Wittmeier et } \\
\text { al }(2013)^{129}\end{array}$ & $\begin{array}{l}\text { Retrospe } \\
\text { ctive }\end{array}$ & 80 & $\begin{array}{l}89 \% \text { First Nations } \\
5 \% \text { Caucasian } \\
6 \% \text { Other }\end{array}$ & $<18$ & $<1$ & Lifestyle monotherapy & 12 & $54 \%$ achieved $\mathrm{HbA} 1 \mathrm{c}<7 \%$ \\
\hline $\begin{array}{l}\text { TODAY Study } \\
\text { Group } \\
(2012)^{138}\end{array}$ & RCT & 699 & $\begin{array}{l}\text { 52.8\% Non-Hispanic } \\
\text { 39.7\% Hispanic } \\
\text { 7.5\% Other }\end{array}$ & $10-17$ & $<1$ & $\begin{array}{l}\text { Group 1: Metformin alone } \\
\text { Group 2: Metformin+Lifestyle } \\
\text { Group 3: } \\
\text { Metformin+Rosiglitazone }\end{array}$ & 45 & $\begin{array}{l}\text { Metformin plus Rosiglitazone significantly } \\
\text { superior to Metformin alone. }\end{array}$ \\
\hline $\begin{array}{l}\text { Yeung et al } \\
(2014)^{141}\end{array}$ & $\begin{array}{c}\text { Cross } \\
\text { sectional }\end{array}$ & 7481 & $\begin{array}{l}\text { South/South east } \\
\text { Asia }\end{array}$ & $\begin{array}{c}<40 \\
\text { (mean age } \\
33 \text { ) }\end{array}$ & 10 & $\begin{array}{l}\text { Insulin treatment alone or in } \\
\text { combination with } \mathrm{OHA}\end{array}$ & $\mathrm{n} / \mathrm{a}$ & Only $27 \%$ of subjects achieved a $\mathrm{HbA} 1 \mathrm{c}<7 \%$ \\
\hline $\begin{array}{l}\text { Jones et al } \\
(2002)^{135}\end{array}$ & RCT & 82 & $\begin{array}{l}\text { 37\% White } \\
30 \% \text { Black } \\
22 \% \text { Hispanic } \\
5 \% \text { Asian } \\
6 \% \text { Other }\end{array}$ & $8-16$ & $\mathrm{n} / \mathrm{a}$ & $\begin{array}{l}\text { Group 1: Metformin } \\
\text { Group 2: Placebo }\end{array}$ & 4 & $\begin{array}{l}\text { The mean HbA1c significantly lower in the } \\
\text { metformin group compared with the placebo } \\
\text { ( } 7.5 \% \text { vs. } 8.6 \% \text {, respectively) }\end{array}$ \\
\hline
\end{tabular}


TABLE 2: Key studies showing the effectiveness of interventions to treat T2DMY. 


\section{Societal impact of T2DMY}

The frequency and severity of complications with T2DMY may limit capacity to work, and c the economic and sociological sequelae are likely to be greater than for later-onset T2DM ${ }^{147}$. Protracted depression requiring substantial on-going psychological support is common with $\mathrm{T}_{2} \mathrm{DMY}^{148}$, and reduced quality of life through visual impairment, frequency of healthcare appointments and lifestyle constraints are prominently cited by younger patients ${ }^{18}$., Pregnancy is not an uncommon occurrence in this age group and the presence of T2DMY can adversely affect maternal and foetal outcomes (Add reference). Chronically disabling and life-threatening co-morbidities such as early onset end-stage renal disease, neuropathic pain and cardiovascular conditions present enormous challenges for patient wellbeing and large potential costs for healthcare provision. The continued escalation of obesity and T2DM in young adults also impinges on the lives of other family members, friends, work colleagues, communities and the prosperity of localities where prevalence is particularly high ${ }^{147,149}$. Early onset obesity and T2DM have also been identified as particular threats to the capacity of healthcare services across Europe and North America, including predictions that current funding systems will not be able to accommodate the growing demands for expensive longterm care incurred by the disease complications ${ }^{3,147,150,151}$. Effective strategies aimed at preventing T2DMY are therefore needed to tackle this problem and the paucity of evidence in this area needs to be addressed urgently (Panel 1 ).

\section{Summary and Future research direction}

While it is tempting to extrapolate the natural history of T2DMY as just an earlier and more rapid form of later-onset T2DM, there are distinctive differences. The T2DMY phenotype has a stronger family history, greater obesity, early loss of both first and second phases of insulin secretion alongside often severe insulin resistance, early onset and rapid progression of micro- and macrovascular complications, and poor sustainability of responsiveness to oral glucose lowering therapies, frequently necessitating early introduction of insulin.

Despite the many recognised genetic and environmental components of T2DMY, further elucidation of individual risk factors and their interactions is required to dissect the pathogenic process more closely and to better inform strategies for prevention and treatment (Panel 2). The paucity of evidence on long-term treatments and outcomes for T2DMY necessitates ongoing conventional clinical investigations to test and refine the use of current interventions. Exploration of more effective ways to implement preventative lifestyle measures in the family setting and to improve health education in the school curriculum will be particularly valuable to enable younger individuals to appreciate the risks and make healthier lifestyle choices. The growing prevalence of T2DMY poses an extra devastating twist to the diabetes pandemic that requires strong public health messaging and investment from all stakeholders to mitigate a pending healthcare disaster.

Panel 2: Knowledge gaps and areas for further research 
Future Research

- Prospective cohort studies to define the natural disease course and heterogeneity of T2DMY

- Elucidation of individual risk factors and their role in the pathogenesis of T2DMY particularly in ethnic populations with high risk

- Randomised control trials to evaluate the effectiveness and safety of currently available therapies

- Research into implementation of preventative measures in family and educational settings

\section{References}

1. International Diabetes Federation. IDF Diabetes Atlas. $7^{\text {th }}$ Edition.

2. Copeland KC, Silverstein J, Moore KR, et al. Management of newly diagnosed type 2 Diabetes Mellitus (T2DM) in children and adolescents. Pediatrics 2013; 131(2): 36482.

3. American Diabetes A. Standards of Medical Care in Diabetes-2016 Abridged for Primary Care Providers. Clin Diabetes 2016; 34(1): 3-21.

4. Organization WH. Definition and diagnosis of diabetes mellitus and intermediate hyperglycaemia: Report of a WHO Consultation.

5. Dabelea D, Mayer-Davis EJ, Saydah S, et al. PRevalence of type 1 and type 2 diabetes among children and adolescents from 2001 to 2009. Jama 2014; 311(17): 1778-86

6. Mayer-Davis EJ, Lawrence JM, Dabelea D, Divers J, Isom S, Dolan L, Imperatore

G, Linder B, Marcovina S, Pettitt DJ, Pihoker C, Saydah S, Wagenknecht L; SEARCH for Diabetes in Youth Study.. Incidence Trends of Type 1 and Type 2 Diabetes 
among Youths, 2002-2012. N Engl J Med. 2017 Apr 13;376(15):1419-1429.

7. Pinhas-Hamiel O, Zeitler P. The global spread of type 2 diabetes mellitus in children and adolescents. J Pediatr 2005; 146(5): 693-700.

8. International Diabetes Federation. IDF Diabetes Atlas. $1^{\text {st }}$ Edition.

9. International Diabetes Federation. IDF Diabetes Atlas. $2^{\text {nd }}$ Edition.

10. International Diabetes Federation. IDF Diabetes Atlas. $3^{\text {rd }}$ Edition.

11. International Diabetes Federation. IDF Diabetes Atlas. $6^{\text {th }}$ Edition.

12. Holden SH, Barnett $A H$, Peters JR, et al. The incidence of type 2 diabetes in the United Kingdom from 1991 to 2010. Diabetes Obes Metab 2013; 15(9): 844-52.

13. D'Adamo E, Caprio S. Type 2 diabetes in youth: epidemiology and pathophysiology. Diabetes Care 2011; 34 Suppl 2: S161-5.

14. Haines L, Wan KC, Lynn R, Barrett TG, Shield JP. Rising incidence of type 2

diabetes in children in the U.K. Diabetes Care. 2007 May;30(5):1097-101.

15. Narayan KM, Boyle JP, Thompson TJ, Sorensen SW, Williamson DF. Lifetime risk for diabetes mellitus in the United States. Jama 2003; 290(14): 1884-90.

16. Kim KS, Oh HJ, Kim JW, et al. The clinical characteristics of the newly diagnosed early onset (< 40 years old) diabetes in outpatients' clinic. Korean Diabetes J 2010; 34(2): 119-25.

17. Chuang LM, Soegondo S, Soewondo P, et al. Comparisons of the outcomes on control, type of management and complications status in early onset and late onset type 2 diabetes in Asia. Diabetes Res Clin Pract 2006; 71(2): 146-55.

18. Jimenez-Corona A, Rojas R, Gomez-Perez FJ, Aguilar-Salinas CA. Early-onset type 2 diabetes in a Mexican survey: results from the National Health and Nutrition Survey 2006. Salud Publica Mex 2010; 52 Suppl 1: S27-35.

19. Alberti G, Zimmet P, Shaw J, et al. Type 2 diabetes in the young: the evolving epidemic: the international diabetes federation consensus workshop. Diabetes Care 2004; 27(7): 1798-811.

20. TODAY Study Group.Effects of metformin, metformin plus rosiglitazone, and 
metformin plus lifestyle on insulin sensitivity and $\beta$-cell function in TODAY.Diabetes Care. 2013 Jun;36(6):1749-57

1. Bacha F, Gungor N, Lee S, Arslanian SA. Progressive deterioration of beta-cell function in obese youth with type 2 diabetes. Pediatr Diabetes 2013; 14(2): 106-11.

2. A. Bagust, S. Beale. Deteriorating beta-cell function in type 2 diabetes: a long-term model Quarterly Journal of Medicine 2003, Volume 96, Issue 4 Pp. 281 - 288

3. Kahn SE. The relative contributions of insulin resistance and beta-cell dysfunction to the pathophysiology of Type 2 diabetes. Diabetologia 2003 Jan;46(1):3-19.

4. Neslihan Gungor, Fida Bacha, Rola Saad, Janine Janosky, and Silva Arslanian. Youth Type 2 Diabetes. Insulin resistance, 6-cell failure, or both? Diabetes Care. 2005 Mar; 28(3): 638-644.

5. Druet $\mathrm{C}$, Tubiana-Rufi N, Chevenne D, Rigal O, Polak M, Levy-Marchal C. Characterization of insulin secretion and resistance in type 2 diabetes of adolescents. J Clin Endocrinol Metab. 2006 Feb;91(2):401-4.

6. Taha D, Umpaichitra V, Banerji MA, Castells S. Type 2 diabetes mellitus in AfricanAmerican adolescents: impaired beta-cell function in the face of severe insulin resistance. J Pediatr Endocrinol Metab 2006; 19(2): 135-42.

7. Mohan $\mathrm{V}$, Amutha $\mathrm{A}$, Ranjani $\mathrm{H}$, et al. Associations of beta-cell function and insulin resistance with youth-onset type 2 diabetes and prediabetes among Asian Indians. Diabetes Technol Ther 2013; 15(4): 315-22.

8. Wilmot E, Idris I. Early onset type 2 diabetes: risk factors, clinical impact and management. Ther Adv Chronic Dis 2014; 5(6): 234-44.

9. Hillier TA, Pedula KL. Characteristics of an adult population with newly diagnosed type 2 diabetes: the relation of obesity and age of onset. Diabetes Care 2001; 24(9): 1522-7.

10. Kahn SE, Hull RL, Utzschneider KM. Mechanisms linking obesity to insulin resistance and type 2 diabetes. Nature. 2006 Dec 14;444(7121):840-6. 
11. Hotamisligil GS, Peraldi P, Budavari A, Ellis R, White MF, Spiegelman BM. IRS-1mediated inhibition of insulin receptor tyrosine kinase activity in TNF-alpha- and obesity-induced insulin resistance. Science 1996; 271(5249): 665-8.

12. Lumeng CN, Saltiel AR. Inflammatory links between obesity and metabolic disease. The Journal of clinical investigation 2011; 121(6): 2111-7.

13. Reinehr $\mathrm{T}^{1}, \underline{\text { Karges }}^{2}, \underline{\text { Meissner }}^{3}, \underline{\text { Wiegand }}^{4}$, $\underline{\text { Stoffel-Wagner }}^{5}, \underline{\text { Holl }}$ RW $^{6}$, Woelfle J ${ }^{7}$.Inflammatory Markers in Obese Adolescents with Type 2 Diabetes and Their Relationship to Hepatokines and Adipokines. J Pediatr. 2016 Jun;173:131-5.

14. Vrachnis N, Antonakopoulos N, Iliodromiti Z, et al. Impact of maternal diabetes on epigenetic modifications leading to diseases in the offspring. Exp Diabetes Res 2012; 2012: 538474.

15. Pettitt DJ, Lawrence JM, Beyer J, et al. Association Between Maternal Diabetes in Utero and Age at Offspring's Diagnosis of Type 2 Diabetes. Diabetes Care 2008; 31(11): 2126-30.

Pettitt DJ, Lawrence JM, Beyer J, Hillier TA, Liese AD, Mayer-Davis B, Loots

B, Imperatore G, Liu L, Dolan LM, Linder B, Dabelea D. Association between

maternal diabetes in utero and age at offspring's diagnosis of type 2 diabetes.

Diabetes Care. 2008 Nov;31(11):2126-30

1. Xinli Jiang, Huijie Ma, ${ }^{2}$ Yan Wang, ${ }^{4}$ and Yan Liu. Early Life Factors and Type 2 Diabetes Mellitus. J Diabetes Res. 2013; 2013: 485082

2. Stettler N, Zemel BS, Kumanyika S, Stallings VA. Infant weight gain and childhood overweight status in a multicenter, cohort study. Pediatrics 2002; 109(2):194-9.

3. Portrait F, Teeuwiszen E, Deeg D. Early life undernutrition and chronic diseases at older ages: the effects of the Dutch famine on cardiovascular diseases and diabetes. Soc Sci Med 2011; 73(5): 711-8.

4. Yessoufou A, Moutairou K. Maternal diabetes in pregnancy: early and long-term outcomes on the offspring and the concept of "metabolic memory". Exp Diabetes Res 2011; 2011: 218598. 
5. Ng M, Fleming $T$, Robinson $M$, et al. Global, regional, and national prevalence of overweight and obesity in children and adults during 1980-2013: a systematic analysis for the Global Burden of Disease Study 2013. Lancet 2014; 384(9945): 76681

6. Steyn NP, Mann J, Bennett PH, et al. Diet, nutrition and the prevention of type 2 diabetes. Public Health Nutr 2004; 7(1A): 147-65.

7. Ebbeling CB, Pawlak DB, Ludwig DS. Childhood obesity: public-health crisis, common sense cure. Lancet 2002; 360(9331): 473-82.

8. Swinburn BA, Sacks G, Hall KD, et al. The global obesity pandemic: shaped by global drivers and local environments. Lancet 2011; 378(9793): 804-14.

9. Megan L. Gow, Sarah P. Garnett, Louise A. Baur, and Natalie B. Lister The Effectiveness of Different Diet Strategies to Reduce Type 2 Diabetes Risk in Youth. Nutrients. 2016 Aug; 8(8): 486.

10. Bray GA, Nielsen SJ, Popkin BM. Consumption of high-fructose corn syrup in beverages may play a role in the epidemic of obesity. Am J Clin Nutr 2004; 79(4): 537-43.

11. Hu FB, Malik VS. Sugar-sweetened beverages and risk of obesity and type 2 diabetes: epidemiologic evidence. Physiol Behav 2010; 100(1): 47-54.

49 Zeid Khitan and Dong Hyun Kim. Fructose: A Key Factor in the Development of Metabolic Syndrome and Hypertension. Journal of Nutrition and Metabolism Volume 2013 (2013), Article ID 682673.

50 Mayer-Davis EJ, Nichols M, Liese AD, et al. Dietary Intake among Youth with Diabetes: The SEARCH for Diabetes in Youth Study. Journal of the American Dietetic Association; 106(5): 689-97.

51 Dollman J, Norton K, Norton L. Evidence for secular trends in children's physical activity behaviour. Br J Sports Med. 2005 Dec;39(12):892-7;

52 Hallal PC, Andersen LB, Bull FC, Guthold R, Haskell W, Ekelund U; Lancet Physical Activity Series Working Group.. Global physical activity levels: surveillance progress, pitfalls, and prospects. Lancet. $2012 \mathrm{Jul}$ 21;380(9838):247-57.

53 Caspersen CJ, Pereira MA, Curran KM. Changes in physical activity patterns in 
the United States, by sex and cross-sectional age. Med Sci Sports Exerc. 2000 Sep;32(9):1601-9.

54 Troiano RP, Berrigan D, Dodd KW, Mâsse LC, Tilert T, McDowell M. Physical activity in the United States measured by accelerometer. Med Sci Sports Exerc. 2008 Jan;40(1):181-8.

55 Riddoch CJ, Bo Andersen L, Wedderkopp N, Harro M, Klasson-Heggeb $\varnothing$ L, Sardinha LB, Cooper AR, Ekelund U. Physical activity levels and patterns of 9- and 15-yr-old European children. Med Sci Sports Exerc. 2004 Jan;36(1):86-92.

56 Gustat J, Srinivasan SR, Elkasabany A, Berenson GS. Relation of self-rated measures of physical activity to multiple risk factors of insulin resistance syndrome in young adults: the Bogalusa Heart Study. J Clin Epidemiol. 2002 Oct;55(10):997-1006

57 Carnethon MR, Gidding SS, Nehgme R, Sidney S, Jacobs DR Jr, Liu K. Cardiorespiratory fitness in young adulthood and the development of cardiovascular disease risk factors. JAMA. 2003 Dec 17;290(23):3092-100.

58 McGavock J, Sellers E, Dean H. Physical activity for the prevention and management of youth-onset type 2 diabetes mellitus: focus on cardiovascular complications. Diab Vasc Dis Res 2007; 4(4): 305-10.

59 Kautiainen S, Koivusilta L, Lintonen T, Virtanen SM, Rimpela A. Use of information and communication technology and prevalence of overweight and obesity among adolescents. Int J Obes (Lond) 2005; 29(8): 925-33.

60 Hulshof KF, Brussaard JH, Kruizinga AG, Telman J, Lowik MR. Socio-economic status, dietary intake and 10 y trends: the Dutch National Food Consumption Survey. Eur J Clin Nutr 2003; 57(1): 128-37.

Marian Abouzeid, Benjamin Philpot, Edward D Janus, Michael J Coates, James A Dunbar. Type 2 diabetes prevalence varies by socio-economic status within and between migrant groups: analysis and implications for Australia. BMC Public Health201313:252.

61 Giles-Corti B, Donovan RJ. Socioeconomic status differences in recreational physical activity levels and real and perceived access to a supportive physical environment. Prev Med 2002; 35(6): 601-11.

62 Delavari M, Sonderlund AL, Swinburn B, Mellor D, Renzaho A. Acculturation and obesity among migrant populations in high income countries--a systematic review. BMC Public Health 2013; 13: 458. 
63 Spencer Bonilla G, Rodriguez-Gutierrez R, V MM. WHat we don't talk about when we talk about preventing type 2 diabetes-addressing socioeconomic disadvantage. JAMA internal medicine 2016; 176(8): 1053-4.

64 Ludwig J, Sanbonmatsu L, Gennetian L, et al. Neighborhoods, Obesity, and Diabetes - A Randomized Social Experiment. New England Journal of Medicine 2011; 365(16): 1509-19.

65 Thomas Reinehr. Type 2 diabetes mellitus in children and adolescents. World J Diabetes. 2013 Dec 15; 4(6): 270-281.

66 Huang TTK, Goran MI. Prevention of type 2 diabetes in young people: a theoretical perspective. Pediatric Diabetes 2003: 4: 38-56

67 Molyneaux L, Constantino M, Yue D. Strong family history predicts a younger age of onset for subjects diagnosed with type 2 diabetes. Diabetes Obes Metab 2004; 6(3): 187-94.

$68 \mathrm{Ng} \mathrm{MC}$, Lee SC, Ko GT, et al. Familial early-onset type 2 diabetes in Chinese patients: obesity and genetics have more significant roles than autoimmunity. Diabetes Care 2001; 24(4): 663-71.

69 Jali MV, Kambar S, Jali SM, Gowda S. Familial early onset of type-2 diabetes mellitus and its complications. N Am J Med Sci 2009; 1(7): 377-80.

70 Frayling TM, Wiltshire S, Hitman GA, et al. Young-onset type 2 diabetes families are the major contributors to genetic loci in the Diabetes UK Warren 2 genome scan and identify putative novel loci on chromosomes $8 q 21,21 q 22$, and 22q11. Diabetes 2003; 52(7): 1857-63.

71 Zhou K, Donnelly LA, Morris AD, et al. Clinical and genetic determinants of progression of type 2 diabetes: a DIRECT study. Diabetes Care 2014; 37(3): 718-24.

72 Krishnan S, Cozier YC, Rosenberg L, Palmer JR. Socioeconomic status and incidence of type 2 diabetes: results from the Black Women's Health Study. Am J Epidemiol 2010; 171(5): 564-70.

73 Lee TC, Glynn RJ, Pena JM, et al. Socioeconomic status and incident type 2 diabetes mellitus: data from the Women's Health Study. PloS one 2011; 6(12): e27670.

74 Hasson RE, Adam TC, Pearson J, Davis JN, Spruijt-Metz D, Goran MI. Sociocultural and socioeconomic influences on type 2 diabetes risk in overweight/obese AfricanAmerican and Latino-American children and adolescents. J Obes 2013; 2013: 512914. 
75 Aguilar-Salinas CA, Reyes-Rodriguez E, Ordonez-Sanchez ML, et al. Early-onset type 2 diabetes: metabolic and genetic characterization in the mexican population. $J$ Clin Endocrinol Metab 2001; 86(1): 220-6.

76 Anuradha S, Radha V, Mohan V. Association of novel variants in the hepatocyte nuclear factor $4 \mathrm{~A}$ gene with maturity onset diabetes of the young and early onset type 2 diabetes. Clin Genet 2011; 80(6): 541-9.

77 Gragnoli C, Menzinger Von Preussenthal G, Habener JF. Triple genetic variation in the HNF-4alpha gene is associated with early-onset type 2 diabetes mellitus in a philippino family. Metabolism 2004; 53(8): 959-63.

78 Tanaka S, Kobayashi T, Tomura $\mathrm{H}$, et al. A novel dominant-negative mutation of the hepatocyte nuclear factor-1alpha gene in Japanese early-onset type 2 diabetes. Horm Metab Res 2000; 32(9): 373-7.

79 - $\quad$ Talbott EO, Zborowski JV, Rager JR, Kip KE, Xu X, Orchard TJ. Polycystic ovarian syndrome (PCOS): a significant contributor to the overall burden of type 2 diabetes in women. J Womens Health (Larchmt) 2007; 16(2): 191-7.

80 Michael L Traub. Assessing and treating insulin resistance in women with polycystic ovarian syndrome. World J Diabetes. 2011 Mar 15; 2(3): 33-40.

81 Joham AE, Ranasinha S, Zoungas S, Moran L, Teede HJ. Gestational diabetes and type 2 diabetes in reproductive-aged women with polycystic ovary syndrome. J Clin Endocrinol Metab 2014; 99(3): E447-52.

82 Nizam S, Khalequzzaman M, Yatsuya $\mathrm{H}$, et al. Incidence of young onset insulinrequiring diabetes mellitus among 18- to 30-year-olds in Dhaka, Bangladesh (19942003). Nagoya J Med Sci 2012; 74(1-2): 149-56.

83 Tulloch-Reid MK, Boyne MS, Smikle MF, et al. Clinical and laboratory features of youth onset type 2 diabetes in Jamaica. West Indian Med J 2010; 59(2): 131-8.

84 Hecht L, Weiss R. Nonalcoholic fatty liver disease and type 2 diabetes in obese children. Current diabetes reports 2014; 14(1): 448.

85 Bloomgarden ZT. Nonalcoholic fatty liver disease and insulin resistance in youth. Diabetes Care 2007; 30(6): 1663-9.

86 Kalra S, Vithalani M, Gulati G, et al. Study of prevalence of nonalcoholic fatty liver disease (NAFLD) in type 2 diabetes patients in India (SPRINT). J Assoc Physicians India 2013; 61(7): 448-53. 
87 Newton KP, Hou J, Crimmins NA, et al. Prevalence of Prediabetes and Type 2 Diabetes in Children With Nonalcoholic Fatty Liver Disease. JAMA Pediatr 2016; 170(10): e161971.

88 Klingensmith GJ, Connor CG, Ruedy KJ, et al. Presentation of youth with type 2 diabetes in the Pediatric Diabetes Consortium. Pediatr Diabetes 2016; 17(4): 266-73.

89 Kelsey MM, Geffner ME, Guandalini C, et al. Presentation and effectiveness of early treatment of type 2 diabetes in youth: lessons from the TODAY study. Pediatr Diabetes 2016; 17(3): 212-21.

90 Saydah SH, Imperatore G, Henkin L, et al. Trends and characteristics of self-reported case presentation of diabetes diagnosis among youth from 2002 to 2010: findings from the SEARCH for diabetes in youth study. Diabetes Care 2015; 38(6): e84-5.

91 Eppens MC, Craig ME, Cusumano J, et al. Prevalence of diabetes complications in adolescents with type 2 compared with type 1 diabetes. Diabetes Care 2006; 29(6): 1300-6.

92 Pinhas-Hamiel O, Zeitler P. Acute and chronic complications of type 2 diabetes mellitus in children and adolescents. Lancet 2007; 369(9575): 1823-31.

93 Copeland KC, Zeitler P, Geffner M, et al. Characteristics of adolescents and youth with recent-onset type 2 diabetes: the TODAY cohort at baseline. J Clin Endocrinol Metab 2011; 96(1): 159-67.

94 Song SH. Complication characteristics between young-onset type 2 versus type 1 diabetes in a UK population. BMJ Open Diabetes Res Care 2015; 3(1): e000044.

95 Mast R, Danielle Jansen AP, Walraven I, et al. Time to insulin initiation and longterm effects of initiating insulin in people with type 2 diabetes mellitus: the Hoorn Diabetes Care System Cohort Study. Eur J Endocrinol 2016; 174(5): 563-71.

96 Adam FMS , Diatri MC, Adam JMF, Seweng A, Tai ES. Prevalence of Metabolic Syndrome in Young Adults. Int J Sci Res 2015, 4. 2319 (IJSR) ISSN (Online): 23197064

97 Song SH, Hardisty CA. Early onset type 2 diabetes mellitus: a harbinger for complications in later years--clinical observation from a secondary care cohort. QJM 2009; 102(11): 799-806. 
98 Gunathilake W, Song S, Sridharan S, Fernando DJ, Idris I. Cardiovascular and metabolic risk profiles in young and old patients with type 2 diabetes. QJM 2010; 103(11): 881-4.

99 Katulanda GW, Katulanda P, Adler Al, et al. Apolipoproteins in diabetes dyslipidaemia in South Asians with young adult-onset diabetes: distribution, associations and patterns. Ann Clin Biochem 2010; 47(Pt 1): 29-34.

100 Song SH. Review: Early-onset type 2 diabetes mellitus: a condition with elevated cardiovascular risk? The British Journal of Diabetes \& Vascular Disease 2008; 8(2): 61-5.

101 Song SH, Gray TA. Early-onset type 2 diabetes: higher burden of atherogenic apolipoprotein particles during statin treatment. QJM 2012; 105(10): 973-80.

102 Huo X, Gao L, Guo L, et al. Risk of non-fatal cardiovascular diseases in earlyonset versus late-onset type 2 diabetes in China: a cross-sectional study. Lancet Diabetes Endocrinol 2016; 4(2): 115-24.

103 Rhodes ET, Prosser LA, Hoerger TJ, Lieu T, Ludwig DS, Laffel LM. Estimated morbidity and mortality in adolescents and young adults diagnosed with Type 2 diabetes mellitus. Diabet Med 2012; 29(4): 453-63.

104 Dabelea D, Stafford JM, Mayer-Davis EJ, D'Agostino R Jr, Dolan L, Imperatore G, Linder B, Lawrence JM, Marcovina SM, Mottl AK, Black MH, Pop-Busui R, SaydahS, Hamman RF, Pihoker C; SEARCH for Diabetes in Youth Research Group.

105 Association of Type 1 Diabetes vs Type 2 Diabetes Diagnosed During Childhood and Adolescence With Complications During Teenage Years and Young Adulthood. JAMA.2017 Feb 28;317(8):825-835.

106 Solis-Herrera C, Triplitt CL, Lynch JL. Nephropathy in youth and young adults with type 2 diabetes. Current diabetes reports 2014; 14(2): 456.

107 Dart AB, Sellers EA, Martens PJ, Rigatto C, Brownell MD, Dean HJ. High burden of kidney disease in youth-onset type 2 diabetes. Diabetes Care 2012; 35(6): 1265-71.

108 Song SH, Gray TA. Early-onset type 2 diabetes: high risk for premature diabetic retinopathy. Diabetes Res Clin Pract 2011; 94(2): 207-11.

109 Song SH. Significant retinopathy in young-onset type 2 vs. type 1 diabetes: a clinical observation. Int J Clin Pract 2016; 70(10): 853-60. 
110 Chuang LM, Soegondo S, Soewondo P, Young-Seol K, Mohamed M, Dalisay E, Go R, Lee W, Tong-Yuan T, Tandhanand S, Nitiyanant W, The-Trach M, Cockram C, Jing-Ping Y. Comparisons of the outcomes on control, type of management and complications status in early onset and late onset type 2 diabetes in Asia. Diabetes Res Clin Pract. 2006 Feb;71(2):146-55. Epub 2005 Jul 6.

111 Dabelea D, Stafford JM, Mayer-Davis EJ, D'Agostino R Jr, Dolan L, Imperatore,G, Linder B, Lawrence JM, Marcovina SM, Mottl AK, Black MH, Pop-Busui R, SaydahS, Hamman RF, Pihoker C; SEARCH for Diabetes in Youth Research Group.Association of Type 1 Diabetes vs Type 2 Diabetes Diagnosed During Childhood and Adolescence With Complications During Teenage Years and Young Adulthood. JAMA.2017 Feb 28;317(8):825-835.

112 Jaiswal M, Lauer A, Martin CL, et al. Peripheral neuropathy in adolescents and young adults with type 1 and type 2 diabetes from the SEARCH for Diabetes in Youth follow-up cohort: a pilot study. Diabetes Care 2013; 36(12): 3903-8.

113 Hillier TA, Pedula KL. Complications in young adults with early-onset type 2 diabetes: losing the relative protection of youth. Diabetes Care 2003; 26(11): 29993005.

114 Luk AOY, Lau ESH, So W-Y, et al. Prospective Study on the Incidences of Cardiovascular-Renal Complications in Chinese Patients With Young-Onset Type 1 and Type 2 Diabetes. Diabetes Care 2014; 37(1): 149-57.

115 Gu W, Huang Y, Zhang Y, et al. Adolescents and young adults with newly diagnosed Type 2 diabetes demonstrate greater carotid intima-media thickness than those with Type 1 diabetes. Diabet Med 2014; 31(1): 84-91.

116 Shah AS, Dolan LM, Kimball TR, et al. Influence of duration of diabetes, glycemic control, and traditional cardiovascular risk factors on early atherosclerotic vascular changes in adolescents and young adults with type 2 diabetes mellitus. $J$ Clin Endocrinol Metab 2009; 94(10): 3740-5.

117 Constantino MI, Molyneaux L, Limacher-Gisler F, et al. Long-Term Complications and Mortality in Young-Onset Diabetes: Type 2 diabetes is more hazardous and lethal than type 1 diabetes. Diabetes Care 2013; 36(12): 3863-9.

118 Lerman-Garber I, Cuevas-Ramos D, Valdes S, et al. Sensorineural hearing loss-a common finding in early-onset type 2 diabetes mellitus. Endocr Pract 2012; 18(4): 549-57.

119 Ren J, Zhao P, Chen L, Xu A, Brown SN, Xiao X. Hearing loss in middle-aged subjects with type 2 diabetes mellitus. Arch Med Res 2009; 40(1): 18-23. 

with type 2 diabetes mellitus? International Urology and Nephrology 2009; 41(4): 777.

121 Nolan JJ. Ageing brain abnormalities in young obese patients with type 2 diabetes: a cause for concern. Diabetologia 2010; 53(11): 2273-5.

122 Willette $\mathrm{AA}, \mathrm{Xu} \mathrm{G}$, Johnson SC, et al. Insulin resistance, brain atrophy, and cognitive performance in late middle-aged adults. Diabetes Care 2013; 36(2): 443-9.

123 Type 2 diabetes in children and adolescents. American Diabetes Association. Diabetes Care 2000; 23(3): 381-9.

124 Nadeau KJ, Anderson BJ, Berg EG, Chiang JL, Chou H, Copeland KC, Hannon TS, Huang TT, Lynch JL, Powell J, Sellers E, Tamborlane WV, Zeitler P. Youth-OnsetType 2 Diabetes Consensus Report: Current Status, Challenges, and Priorities.Diabetes Care. 2016 Sep;39(9):1635-42.

125 Garber AJ, Abrahamson MJ, Barzilay JI, et al. Consensus Statement by the American Association of Clinical Endocrinologists and American College of Endocrinology on the Comprehensive Type 2 Diabetes Management Algorithm-2016 Executive Summary. Endocr Pract 2016; 22(1): 84-113.

126 Wittmeier KD, Wicklow BA, Sellers EA, Griffith AT, Dean HJ, McGavock JM. Success with lifestyle monotherapy in youth with new-onset type 2 diabetes. Paediatr Child Health 2012; 17(3): 129-32.

127 Willi SM, Martin K, Datko FM, Brant BP. Treatment of type 2 diabetes in childhood using a very-low-calorie diet. Diabetes Care 2004; 27(2): 348-53.

128 Burns N, Finucane FM, Hatunic M, et al. Early-onset type 2 diabetes in obese white subjects is characterised by a marked defect in beta cell insulin secretion, severe insulin resistance and a lack of response to aerobic exercise training. Diabetologia 2007; 50(7): 1500-8.

129 Jonathan McGavock, Allison Dart and Brandy Wicklow. Lifestyle Therapy for the Treatment of Youth with Type 2 Diabetes. Curr Diab Rep. 2015; 15: 568. 
130 Jones KL, Arslanian S, Peterokova VA, Park JS, Tomlinson MJ. Effect of metformin in pediatric patients with type 2 diabetes: a randomized controlled trial. Diabetes Care 2002; 25(1): 89-94.

131 Gaylor AS, Condren ME. Type 2 diabetes mellitus in the pediatric population. Pharmacotherapy 2004; 24(7): 871-8.

132 George MM, Copeland KC. Current treatment options for type 2 diabetes mellitus in youth: today's realities and lessons from the TODAY study. Current diabetes reports 2013; 13(1): 72-80.

133 TODAY Study Group., Zeitler P, Hirst K, Pyle L, Linder B, Copeland K, Arslanian S, Cuttler L, Nathan DM, Tollefsen S, Wilfley D, Kaufman F. A clinical trial to maintain glycemic control in youth with type 2 diabetes. N Engl J Med. 2012 Jun 14;366(24):2247-56.

134 Miglani S, Goswami R, Tandon N, Dudha A, Kochupillai N. Glycaemic control and microvascular complication among patients with youth onset diabetes in India using differing types of insulin and methods of glucose monitoring. Diabetes Research and Clinical Practice; 65(2): 183-5.

135 Donovan PJ, McIntyre HD. Achievement of cardiovascular risk factor targets in young adults with diabetes mellitus. Diabetes Metab Syndr Obes 2010; 3: 387-94.

136 Yeung RO, Zhang Y, Luk A, et al. Metabolic profiles and treatment gaps in young-onset type 2 diabetes in Asia (the JADE programme): a cross-sectional study of a prospective cohort. Lancet Diabetes Endocrinol 2014; 2(12): 935-43.

137 Benhalima K, Song SH, Wilmot EG, et al. Characteristics, complications and management of a large multiethnic cohort of younger adults with type 2 diabetes. Prim Care Diabetes 2011; 5(4): 245-50.

138 Reinehr T, Schober E, Roth CL, Wiegand S, Holl R, Group DP-WS. Type 2 diabetes in children and adolescents in a 2-year follow-up: insufficient adherence to diabetes centers. Horm Res 2008; 69(2): 107-13.

139 Tahrani AA, Barnett AH, Bailey CJ. Pharmacology and therapeutic implications of current drugs for type 2 diabetes mellitus. Nature Reviews Endocrinology 2016, 12, 566-592. 
141 Dixon JB, le Roux CW, Rubino F, Zimmet P. Bariatric surgery for type 2 diabetes. Lancet. 2012 Jun 16;379(9833):2300-11.

142 Mingrone G. Pros and cons of bariatric surgery in adolescents. Lancet DiabetesEndocrinol. 2017 Jan 5. pii: S2213-8587(16)30425-9.

143 Serrano OK, Zhang Y, Kintzer E, Moran-Atkin E, Choi J, Melvin WS, Camacho DR.Outcomes of bariatric surgery in the young: a single-institution experience caring for patients under 21 years old. Surg Endosc. 2016 Nov;30(11):5015-5022.

144 Marie-Claude Breton, Line Guénette, Mohamed Amine Amiche, JeanneFrançoise Kayibanda, Jean-Pierre Grégoire, and Jocelyne Moisan. Burden of Diabetes on the Ability to Work: a systematic review. Diabetes Care 2013 Mar; 36(3): 740-749

145 Browne JL, Nefs G, Pouwer F, Speight J. Depression, anxiety and self-care behaviours of young adults with Type 2 diabetes: results from the International Diabetes Management and Impact for Long-term Empowerment and Success (MILES) Study. Diabet Med 2015; 32(1): 133-40.

146 Klingensmith GJ, Pyle L, Nadeau KJ, Barbour LA, Goland RS, Willi SM, Linder B, White NH; TODAY Study Group.. Pregnancy Outcomes in Youth With Type 2 Diabetes: The TODAY Study Experience. Diabetes Care. 2016 Jan;39(1):122-9.

148 Day C. The Policy Puzzle: the diabetes maze in Europe. The British Journal of Diabetes \& Vascular Disease 2011; 11(6): 273-5.

149 Merlotti C, Morabito A, Pontiroli AE. Prevention of type 2 diabetes; a systematic review and meta-analysis of different intervention strategies. Diabetes, Obesity and Metabolism 2014; 16(8): 719-27.

150 Kaufman F. Preventing type 2 diabetes in children - a role for the whole community Diabetes Voice 2007, 52, 35-8.

151 Libman IM, Arslanian SA. Prevention and treatment of type 2 diabetes in youth. Horm Res. 2007;67(1):22-34 
152 Hills S, Halban PA. DIAMAP: A Road Map for Diabetes Research in Europe. Journal of Diabetes Science and Technology 2011; 5(3): 794-7.

\section{AUTHORS AND CONTRIBUTORS}

Dr Lascar, Dr Brown and Dr Bailey conducted the literature search. Dr Lascar and Dr Bellary wrote the initial draft of the paper. Dr Brown, Dr Pattison, Dr Bailey and Dr Barnett critically revised and edited the paper.

All the authors approved the final manuscript.

\section{DECLARATION OF INTERESTS}

Dr Lascar, Dr Brown and Dr Pattison have nothing to disclose.

Dr Barnett reports personal fees from MSD, personal fees from Novartis, personal fees from Boehringer-Ingelheim, personal fees from Janssen, personal fees from Astra-Zeneca, personal fees from NovoNordisk, personal fees from Eli Lilly, personal fees from Sanofi-Aventis, outside the submitted work.

Dr Bailey reports personal fees from AstraZeneca, Boehringer Ingelheim, Elcelyx, Lexicon, Poxel, Eli Lilly, Janssen, MSD, Novo, Sanofi-Aventis, outside the submitted work.

Dr Bellary reports grants from The Binding Site Ltd, grants from NovoNordisk, UK Ltd, during the conduct of the study; personal fees from AstraZeneca, personal fees and other from Boehringer Ingelheim, personal fees from MSD, grants, personal fees and other from NovoNordisk Ltd, personal fees from Janssen, personal fees and other from Eli Lilly, personal fees and other from SanofiAventis, outside the submitted work.

\section{ROLE OF THE FUNDING SOURCE}

Received grants from The Binding Site and NovoNordisk UK Ltd, which fund the research fellow post. However, the funders had no input into the preparation of this manuscript.

Dr Bellary had final responsibility for the decision to submit for publication. 